\begin{tabular}{|c|c|}
\hline 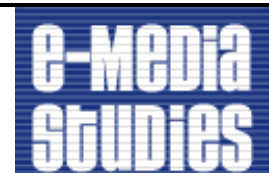 & $\begin{array}{l}\text { Journal of e-Media Studies } \\
\text { Volume 3, Issue 1, } 2013 \\
\text { Dartmouth College }\end{array}$ \\
\hline
\end{tabular}

\title{
Review of Old Maps Online
}

Alyssa McLeod

Labeled "Google for old maps" by its creators, the Jisc-funded Old Maps Online is an interface powered by Google Maps that allows users to search for fully digitized historical maps hosted by external institutions ranging from the National Library of Scotland's map library to the online David Rumsey Historical Map Collection centered on North and South America. Co-creators Klokan Technologies and the University of Portsmouth's Great Britain Historical Geographical Information System encourage users to contribute old maps they possess, provided that highresolution scans of the maps are available online in open access form, and real-world coordinates for the outside corners of the maps have been established.

Old Maps Online's diverse search functions (supported by Klokan's innovative MapRank Search technology) integrate the benefits of happenstance and specificity, allowing the user to either pan in on a world map or search for a particular location by place name or area code. Thumbnail images of historical maps that have been georeferenced to the area in question are automatically generated at the right-hand side of the screen, and the site's well-designed time slider bar provides a means of further narrowing the search field. Once clicked, each thumbnail image will direct the user to the map's host institution. 


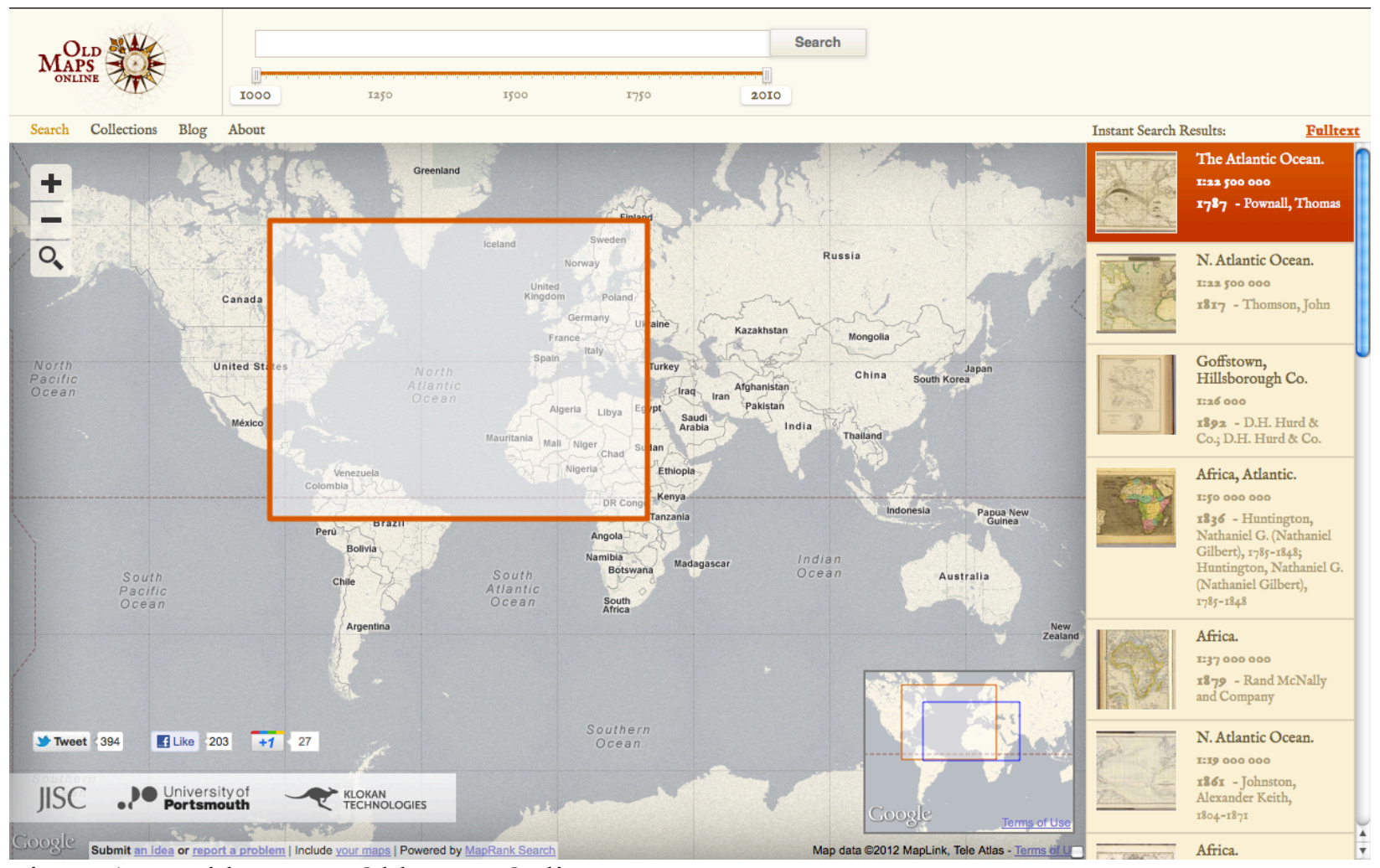

Figure 1. World map on Old Maps Online 


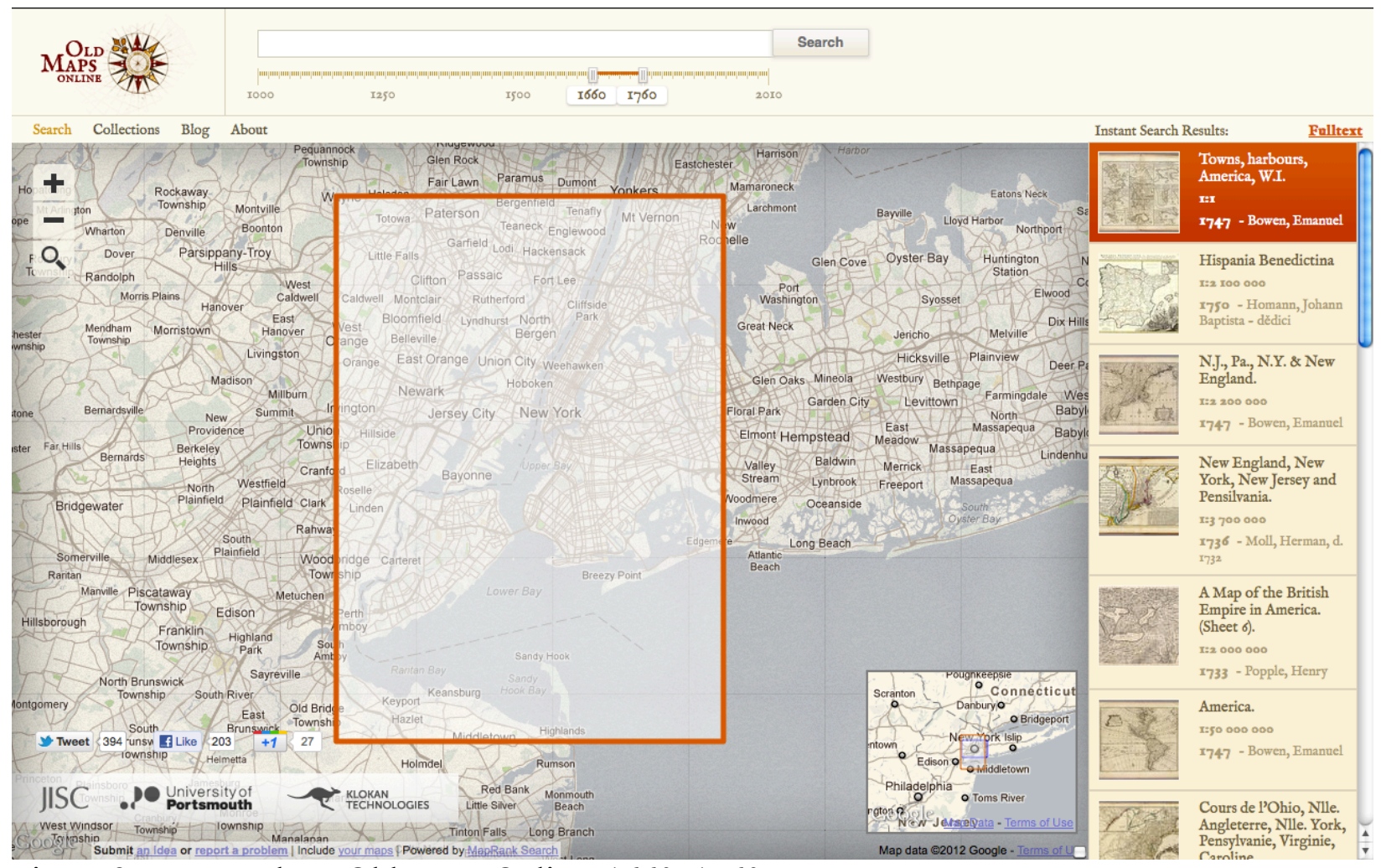

Figure 2. New York on Old Maps Online, 1660-1760

Search

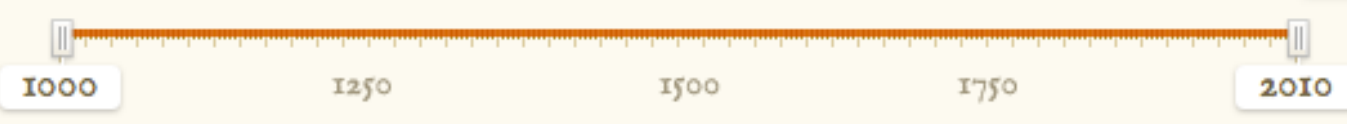

Figure 3. Time slider bar

\section{A User-friendly Gateway}

Although the current version of Old Maps Online went live in early 2012, its developers have been leading GIS (geographic information system) workshops at conferences for the past few years, officially launching the site on February 29, 2012, at an Association of American

Geographers' conference in New York City, and, simultaneously, at the Gerald Aylmer Seminar in London. This constant workshopping with geographers, archivists, and librarians has had a 
definitive impact on the project's quality: Old Maps Online's interface is by and large intuitive, easy to manipulate, and aesthetically appealing, and it supports existing metadata standards, including Dublin Core, FGDC (Federal Geographic Data Committee), and MARC (Metadata Object Description Schema).

Much of the project's beauty lies in its minimalist approach to the dissemination of information. The site is essentially a search interface that facilitates a uniquely spatial means of exploring online archival repositories. Apart from providing detailed metadata for each thumbnail image, Old Maps Online leaves the analysis and contextual information about each map to the library that hosts the image. This reliance on other data hosts could potentially create problems, of course, should a library website go off-line, although the project backs up map titles, dates, URLs, and coordinates in spreadsheet form (see submission instructions). Old Maps Online functions as a scholarly indexing tool for material already available online.

The project similarly owes much of its usability to its reliance on Google Maps API, which, though a proprietary tool, has become the standard of navigable online maps. Because Old Maps Online can remain open source only until its funding runs out in 2013 (see submission instructions), and because Google Code is freely available only to sites that are free to consumers, it should prove interesting to see how the interface may change in a year's time. The site has already experienced several server issues related to its use of AddThis, an open source social bookmarking tool. "We are an academic project aiming to provide a popular service to a wide audience that is free of charge to both map libraries and map users, and funded by a relatively small one-off project grant," explains Humphrey Southall of the University of 
Portsmouth in a blog post on March 6, 2012, adding that this commitment to open access makes the project "dependent" on other services.

Given that Old Maps Online is a relatively new project, certain locations on the site's world map have a limited number of historical maps available, a temporary problem that the site's search function could address more directly. For example, a search for maps of "Victoria, BC" between the years 1700 and 1900 turns up only a few maps in the sidebar that, at closer glance, turn out to represent most of North America instead of the municipality of Victoria or even the northern part of the continent. More content could easily address this issue, and the project's developers have made it clear that they encourage feedback. That being said, the site has already attracted much attention from the urban studies community, including Ottawa's Spacing magazine, and will certainly benefit from the input and resources of local historians and scholars. 


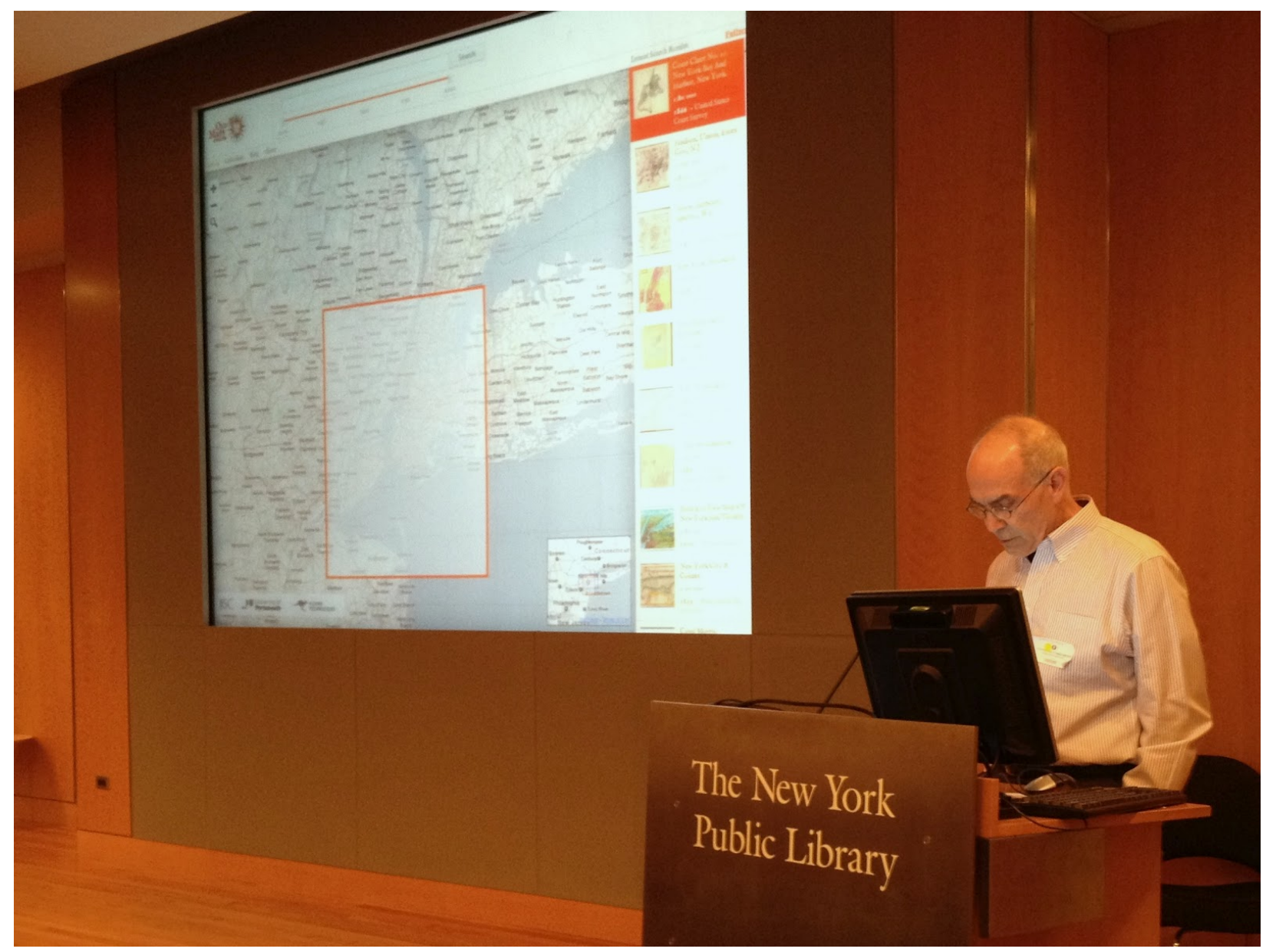

Figure 4. February 29, 2012, keynote in New York City

$\operatorname{cm} \perp>$

<head>

<title>old Maps Online</title>

$<$ meta charset $="$ utf $-8 ">$

<meta name="description" content $="$ ">

<meta name $="$ keywords" content $="$ ">

$<$ meta name="google" value="notranslate">

<link rel="stylesheet" href="/css/main.css" media="screen,projection">

$<$ ink rel $="$ stylesheet $"$ href $="$ /css/print.css" media $=$ "print" >

$<!--[$ if lte IE 8] $><$ link rel="stylesheet" href="/CSS/ie.cSs" $><![e n d i f]-->$

<meta http-equiv="X-UA-Compatible" content $="$ chrome=1" />

<meta http-equiv="X-UA-Compatible" content="IE=8" />

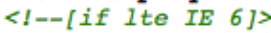

<meta http-equiv="refresh" content="0; url=http://www.ie6countdown.com/" />

<script type="text/javascript" >window.top.location = 'http://www.ie6countdown.com/'; $\langle/$ script $\rangle$

$<$ ! [endif] -->

<script type="text/javascript" src="http://www.google.com/jsapi" $\rangle\langle/$ script>

<script type="text/javascript" src="http://maps.google.com/maps/api/js?v=3.3\&sensor=false" $>\langle/$ script>

$\langle$ script $\mathbf{s r c}="$ /index.js $"></$ script $>$

$</$ head $>$

<body>

<div id="container">

Figure 5. Google Maps API code 


\section{Project History}

One of the most fascinating aspects of this project is the ready availability of its history, outlined on a blog appended to the Old Maps Online site. Backed by the Ministry of Culture of the Czech Republic, a previous incarnation of this project at the Moravian Library in Brno aimed in 2008 to develop online georeferencing and rectifier tools that would generate geo-metadata automatically, allowing users to search for historical maps overlaid on top of a map of the world. Part of the original project's goal was to outline a map cataloging process that could be easily imitated by other scholars; the blog shares in detail the research group's workflow process and the different forms of software with which they experimented, including MapAnalyst and Microsoft Research MapSynthesizer. Petr Pridal, still involved with the site through Klokan Technologies, even went so far as to make the group's code publicly available.

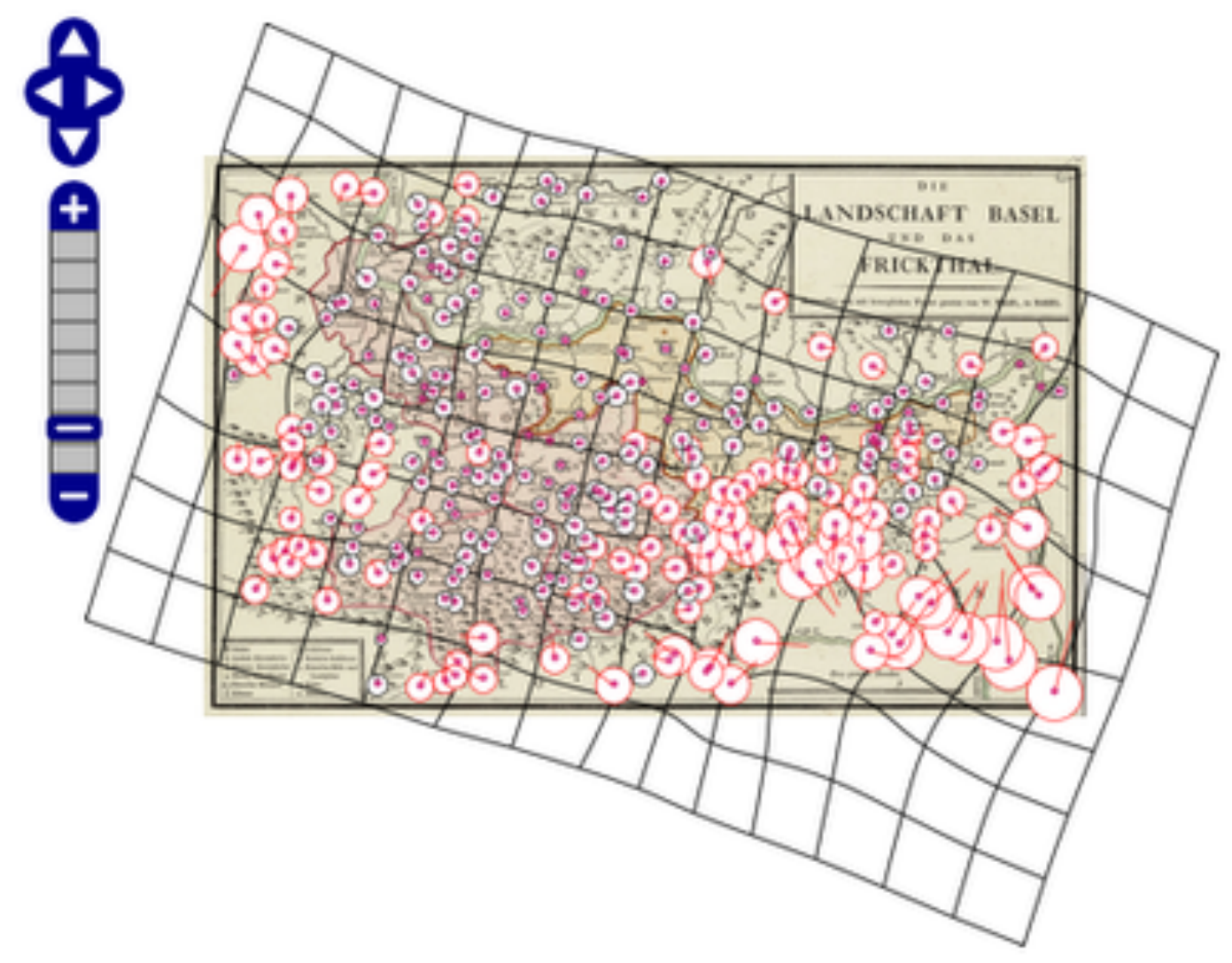

Figure 6.

MapAnalyst in action 
Although now operated by a partnership between a British university and a Switzerland-based software company, Old Maps Online still participates in this kind of collaborative activity. With the aid of the free online Georeferencer tool, users of the British Library online map collection helped define the coordinates of more than 700 maps for Old Maps Online in under a week in February 2012, saving the project months of time and effort. The British Library repeated its crowdsourcing efforts in November 2012 and January 2013, georeferencing over 2,400 maps by the spring of 2013.

As well as an excellent search tool for anyone researching the historical understanding of space, Old Maps Online is an excellent model for future digital projects, providing a compelling argument for the efficiency and usability of crowdsourced projects. The project will undoubtedly prove to be an invaluable resource for researchers and a helpful pedagogical tool for teachers at the secondary and postsecondary levels.

\section{About the Author}

Alyssa McLeod recently completed a master's degree in English literature and the digital humanities at the University of Victoria, where she studied subjective time and space in 14thcentury alliterative poetry, focusing particularly on the digital representation of poetic geotemporality. She is currently working as a front-end web developer for the Royal British Columbia Museum. 

Published by the Dartmouth College Library. http://journals.dartmouth.edu/joems/
Article DOI: 10.1349/PS1.1938-6060.A.431 